\title{
INFLUÊNCIA DA APLICAÇÃO DE CÁLCIO E ALAGAMENTO DO SOLO SOBRE CARACTERÍSTICAS ANATÔMICAS DAS FOLHAS DE MILHO (Zea mays L.) "SARACURA" BRS-4154
}

\author{
HYRANDIR CABRAL DE MELO ${ }^{1}$, EVARISTO M. DE CASTRO $^{2}$, JORGE LUIS ROMERO $^{3}$, JOSÉ $^{-}$ \\ DONIZETE ALVES ${ }^{4}$, DANIELA DEITOS FRIES ${ }^{5}$, LUCAS AMARAL DE MELO ${ }^{6}$, PAULO CÉSAR \\ MAGALHÃES?
}

\author{
${ }^{1}$ Pós-graduando, Ms, Universidade Federal de Lavras. Caixa postal 37, CEP. 37200-000 Lavras, MG. E-mail: \\ hyrandir@bol.com.br \\ ${ }^{2}$ Prof ${ }^{o}$. do Depto. de Biologia, Universidade Federal de Lavras. Caixa Postal 37, CEP. 37200-000 Lavras, MG. E-mail: \\ emcastro@ufla.br (autor para correspondência) \\ ${ }^{3}$ Corporação Colombiana de Investigação Agropecuária (CORPOICA) \\ ${ }^{4}$ Prof ${ }^{o}$ do Depto. de Biologia, Universidade Federal de Lavras. Caixa Postal 37, CEP. 37200-000 Lavras, MG. \\ ${ }^{5}$ Pós-graduanda, Dra., Universidade Federal de Lavras. \\ ${ }^{6}$ Estudante de Iniciação Científica, Universidade Federal de Lavras. \\ ${ }^{7}$ Bolsista do CNPq, Pesquisador, Embrapa Milho e Sorgo. Caixa postal 151, CEP. 35701-970 Sete Lagoas, MG.
}

Revista Brasileira de Milho e Sorgo, vol.3, n.3, p.333-342, 2004

\begin{abstract}
RESUMO - A cultivar de milho "Saracura" BRS-4154 apresenta-se tolerante às condições de hipoxia decorrentes do encharcamento do solo. Alterações fisiológicas e anatômicas estão envolvidas no processo de adaptação de plantas a ambientes com baixa pressão de oxigênio. Ao mesmo tempo, o cálcio, além de ser um elemento estrutural que participa dos constituintes da parede celular, mostrou-se eficiente no aumento da tolerância de plantas do milho "Saracura" submetidas a estresse gasoso. O objetivo deste trabalho foi avaliar as alterações morfo-anatômicas das folhas da cultivar de milho "Saracura" sob influência da aplicação de cloreto de cálcio e alagamento do solo em plantas em estádio de floração. O experimento foi conduzido em casa de vegetação, cujos tratamentos consistiram na aplicação ou não de cálcio ao solo com irrigação normal ou alagamento. Cortes transversais e paradérmicos foram preparados de acordo com as técnicas usuais de microtécnica vegetal. Foram observadas alterações significativas para o tamanho dos estômatos, ângulo de curvatura de lâmina foliar, diâmetro polar de células buliformes e espessura de nervura mediana, feixe vascular, metaxilema, mesofilo, epiderme das superfícies adaxial e abaxial.
\end{abstract}

Palavras-chave: Poaceae, hipoxia, nutriente, morfologia.

\section{EFFECTS OF CALCIUM AND SOIL FLOODING ON ANATOMICAL CHARACTERISTICS OF SARACURA BRS-4154 MAIZE (Zea mays L.) LEAVES}

\begin{abstract}
The Saracura BRS-4154 maize cultivar presents tolerance to hypoxia conditions coming from soil flooding. Physiological and anatomical alterations are involved on plants adaptation process to environments with low oxygen pressure. At the same time, calcium, besides being a structural element which participates of cell wall constituents, increased the tolerance of the saracura maize plants submitted to gaseous
\end{abstract}


stress. The objective of this work was to evaluate the morph-anatomical alterations of saracura maize leaves, under influence of calcium chloride application and soil flooding in plants at flowering stage of growth. The experiment was carried out at green house and treatments were held either with or without calcium application in normally irrigated or flooded soil. Transversal cuts and paradermical were prepared according to usual techniques of plant micro technique. The data collected showed significant alterations for stomata's size, curvature angle of leaf blade, polar diameters of bulliform cells and median thickness of nervure, vascular bundle, metaxylem, mesophyll, adaxial and abaxial epidermal.

Key words: Poaceae, hypoxia, nutrient, morfology.

Em solos alagados, os poros anteriormente ocupados pelo ar passam a ser ocupados pela água e o pouco oxigênio remanescente na solução do solo é rapidamente consumido pelas raízes das plantas e microbiota do solo (Drew e Lynch, 1988), resultando em estresse às plantas causado pelo decréscimo da concentração de oxigênio no meio (Jackson e Drew, 1984). No entanto, existem espécies que em condições de estresse gasoso adaptam-se morfo-anatomicamente ou metabolicamente à anoxia (Drew e Lynch, 1988).

Poucos são os trabalhos que relatam as mudanças estruturais em folhas que contribuam para a adaptabilidade de plantas a condições de inundação do solo. Vasellati et al., 2001, atribuíram a maior formação de aerênquimas na bainha foliar de Paspalum dilatatum como um fator adaptativo desta espécie às condições de hipoxia/ anoxia. Stoyanova et al. (2002) observaram que algumas alterações anatômicas em folhas de milho submetido a condições de inundação se assemelham às alterações de quando submetido a condições de deficiência de água no solo.

Diferentes graus de tolerância das plantas em condições de solos inundados e/ou encharcados variam entre espécies (Gibbs e Leitão Filho, 1978; Kozlowski, 1984) e entre genótipos da mesma espécie (Gill, 1970). A cultivar de milho "Saracura" foi caracterizada como tolerante a períodos intermitentes de alagamento do solo por ser menos suscetível a alterações no desenvolvimento vegetativo e reprodutivo (Parentoni et al., 1995).

A maior tolerância à baixa pressão de oxigênio está relacionada ao metabolismo de parede celular (Grant et al., 1973; Damarty et al., 1984). O cálcio, como elemento estrutural, participa de ligações covalentes entre os grupos carboxílicos dos ácidos poligalacturônicos, constituintes da parede celular (Grant et al., 1973; Damarty et al., 1984). A adição de cloreto de cálcio à solução de germinação promoveu um aumento na sobrevivência das plântulas tanto da cultivar "Saracura" como da variedade BR-107 classificada como não tolerante às condições de hipoxia (Vitorino et al., 2001). No caso do milho "Saracura", o aumento na sobrevivência foi atribuído à redução do crescimento das raízes em até $37 \%$ em relação ao controle (Alves et al., 2002).

O cálcio é conhecido como um mensageiro secundário em resposta às diferentes condições de estresse (Hepler e Wayne, 1985; Smallwood et al., 1999), além de ser o único elemento mineral que possui atividade apoplástica (Seling et al., 2000). Nas condições de deficiência de oxigênio, ocorre uma elevação na concentração de cálcio no citoplasma (Subbaiah et al., 1994a) e a variação dessa concentração precede a expressão de genes que codificam peptídeos anaeróbicos (Subbaiah et al., 1994b). 
O objetivo deste trabalho foi avaliar as alterações morfo-anatômicas das folhas da cultivar de milho "Saracura" sob influência da aplicação de cloreto de cálcio e alagamento do solo em plantas em estádio de floração.

\section{Material e Métodos}

Sementes do milho "Saracura" BRS4154, ciclo 14, foram utilizadas para o ensaio, conduzido em casa de vegetação na Embrapa Milho e Sorgo, localizada no município de Sete Lagoas, MG. Esta localidade apresenta uma altitude de 732 m, latitude Sul 19²8', longitude Oeste $44^{\circ} 15^{\prime}$. Durante o período de avaliação, as temperaturas máxima e mínima no interior da casa de vegetação variaram de 30 a $36^{\circ} \mathrm{C}$ e 9,5 a $15,5^{\circ} \mathrm{C}$ respectivamente. A umidade relativa do ar oscilou entre 52 a $78 \%$. Utilizaram-se duas plantas por vaso com $20 \mathrm{Kg}$ de solo de várzea classificado como Neossolo Flúvico Tb, Eutrófico Típico, textura argilosa, fase relevo plano campos de várzea (Empresa Brasileira de Pesquisa Agropecuária, 1999). A adubação foi feita de acordo com resultados da análise química, aplicando-se no momento do plantio uma adubação básica com 5-20-20+Zn em doses de $23 \mathrm{~g} .20 \mathrm{Kg}^{-1}$ de solo. Os tratamentos foram constituídos pela adição de $300 \mathrm{Kg} \cdot \mathrm{ha}^{-1}$ de cloreto de cálcio incorporado ao solo na época do plantio. Cada tratamento foi avaliado em condições normais de irrigação e sob condições de encharcamento do solo imposto a partir do estádio V6 até a floração. O tratamento controle foi conduzido com irrigação normal e sem a adição de cloreto de cálcio ao solo. As avaliações foram realizadas na floração, utilizando-se a segunda folha completamente expandida, a partir do ápice. Após retiradas, foram fixadas em FAA 70 (formaldeído, ácido acético e álcool etílico) por 72 horas e posteriormente conservadas em álcool
$70 \%$ (Johansen, 1940). Os cortes transversais foram realizados à mão livre de seções do terço médio foliar, clarificados com água sanitária 5\% (Kraus e Arduim, 1997) e corados com uma mistura de azul de astra e safranina (Kraus e Arduim, 1997). Os cortes paradérmicos foram realizados manualmente e corados com safranina $1 \%$. $\mathrm{O}$ número de estômatos por $\mathrm{mm}^{2}$ foi determinado na região mediana da folha de acordo com Laboriau et al. (1961). As determinações de espessura de células e tecidos foram realizadas utilizando-se uma ocular micrométrica. Utilizaramse quatro campos por indivíduo, em cinco indivíduos por tratamento, para a determinação da densidade estomática e para a mensuração de células e tecidos. As avaliações na lâmina foliar foram realizadas após quatro feixes vasculares de maior calibre, partindo da região da nervura mediana em direção à borda foliar, quando era atingida uma maior uniformidade da espessura da lâmina foliar. Como padrão para as avaliações de diâmetro de feixe vascular e metaxilema, utilizou-se os feixes ocorrentes na porção basal mais central da nervura mediana. A espessura do mesofilo foi medida em locais intermediários aos feixes vasculares de maior diâmetro. Observouse visualmente, e com auxílio de microscópio de luz, a curvatura das lâminas foliares em relação à nervura mediana. Glicerina $50 \%$ foi utilizada para montagem das lâminas e as fotomicrografias feitas ao fotomicroscópio Olympus BX-60.

Após a análise de variância, foi utilizado o teste de Tukey a 5\% de probabilidade para separação das médias em classes distintas.

\section{Resultados e Discussão}

Mudança na curvatura das lâminas foliares em relação à nervura mediana foi observada em todas as plantas que foram alagadas e naquelas que estiveram na presença do cálcio, 
fechando em forma de $\mathrm{V}$ na superfície adaxial (Figura 1B, 1C, 1D). Entretanto, nas plantas que não receberam cálcio e não foram alagadas, a disposição laminar das folhas praticamente não mudou em relação a posição da nervura mediana (Figura 1A).

De acordo com Esau (2000), tanto o dobramento quanto o enrolamento das folhas estão associados à atuação de células motoras, as células buliformes, as quais apresentaram grandes dimensões em todos os tratamentos (Figura 1M, $1 \mathrm{~N}, 1 \mathrm{O}, 1 \mathrm{P})$. Essas células foram encontradas na epiderme da superfície adaxial em grupos de duas a quatro, cujo diâmetro equatorial apresentou-se numericamente maior que o polar (Tabela 2). Grupos de duas a cinco células buliformes foram observados para a cultivar de milho Knezha 611 2L, por Stoyanova et al. (2002). Quando comparado o diâmetro polar do grupo de células buliformes entre os tratamentos, observou-se que

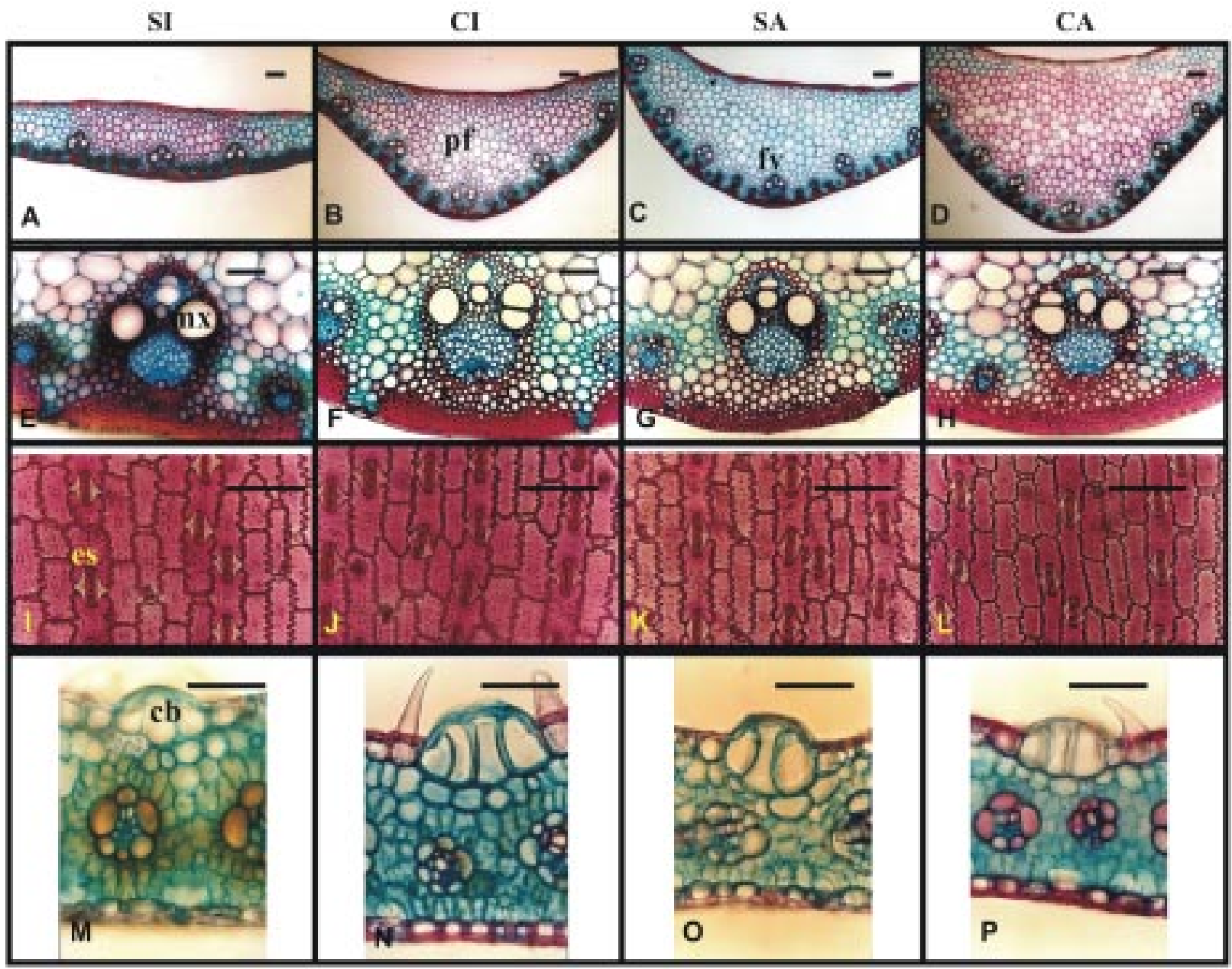

FIGURA 1. Fotomicrografias de folhas de plantas de milho "Saracura". Seção transversal da nervura mediana com detalhe de parênquima fundamental (pf) (A, B, C e D); seção transversal da nervura mediana com detalhe do feixe vascular basal (fv) e metaxilema $(\mathrm{mx})(\mathrm{E}, \mathrm{F}, \mathrm{G}$ e H); seção paradérmica da epiderme abaxial com detalhe dos estômatos (es) (I, J, K e L); seção transversal da lâmina foliar com detalhe de células buliformes (cb) (M, N, O e P). SI, sem cálcio com irrigação normal; CI, com cálcio com irrigação normal; SA, sem cálcio e alagado; CA, com cálcio e alagado. Barras $=100 \mu \mathrm{m}$. 
esse foi significativamente maior nas plantas que não receberam cálcio e foram alagadas (Tabela 2).

Apesar de não haver diferenças na densidade estomática entre os tratamentos (Tabela 1), observou-se na epiderme abaxial valores de densidade estomática ligeiramente maiores que na epiderme adaxial. Houve variação no tamanho dos estômatos, tanto em relação ao diâmetro polar quanto ao equatorial. Os estômatos da superfície abaxial das folhas de plantas que receberam cálcio apresentaram um diâmetro polar menor que daquelas que não receberam, sendo significativo no tratamento em que a irrigação foi normal. $\mathrm{O}$ mesmo foi observado no diâmetro equatorial em relação ao tratamento controle, sem cálcio e irrigação normal. Entretanto, ao analisar os tratamentos que foram alagados, percebeu-se que nas plantas que não receberam cálcio ocorreu o menor diâmetro equatorial dos estômatos, e naquelas que estiveram na presença do cálcio, esse diâmetro tendeu, numericamente, a aproximar daquele observado no tratamento controle. Ao mesmo tempo, os diâmetros equatoriais dos estômatos da superfície adaxial de plantas que estiveram na presença do cálcio, apresentaram-se significativamente maiores que daquelas na ausência desse elemento, independente do alagamento (Tabela 1, Figuras $1 \mathrm{I}, 1 \mathrm{~J}, 1 \mathrm{~K}, 1 \mathrm{~L})$.

Uma característica muito variável em plantas de acordo com o ambiente é a densidade e o tamanho dos estômatos. Segundo Menezes et al. (2003), o número de estômatos por área tornou-se maior em plantas submetidas à deficiência de água. Esses parâmetros também são importantes indicadores para plantas submetidas à poluição atmosférica (Bennett et al., 1992), à salinidade (Flowers et al., 1986) e a elevadas temperaturas (Sachs et al., 1993). Alves et al. (2001), estudando o efeito de poluentes na anatomia foliar de um híbrido de Trandescantia, observaram que a redução no tamanho dos estômatos ocorreu apenas na epiderme abaxial, sendo esta mais sensível e mais responsiva às alterações do meio. Segundo Larcher (2000), além do número, o tamanho dos estômatos é um fator importante na regulação do fechamento estomático. Tanto a frequência quanto o comportamento dos estômatos são características importantes para a seleção de cultivares de milho resistentes ao estresse hídrico (Magalhães et al., 2002).

TABELA 1. Densidade estomática e tamanho dos estômatos nas epidermes adaxial e abaxial de milho "Saracura" na época de floração, submetido às condições de alagamento e aplicação de cálcio ao solo. Lavras, 2004.

\begin{tabular}{ccccccc}
\hline Trat. & $\begin{array}{c}\text { DEEAb } \\
\left(\mathbf{m m}^{2}\right)\end{array}$ & $\begin{array}{c}\text { DPEEAb } \\
(\mu \mathrm{m})\end{array}$ & $\begin{array}{c}\text { DEEEAb } \\
(\mu \mathrm{m})\end{array}$ & $\begin{array}{c}\text { DEEAd } \\
\left(\mathbf{m m}^{2}\right)\end{array}$ & $\begin{array}{c}\text { DPEEAd } \\
(\mu \mathrm{m})\end{array}$ & $\begin{array}{c}\text { DEEEAd } \\
(\mu \mathrm{m})\end{array}$ \\
\hline SI & $118.4 \mathrm{a}$ & $45.6 \mathrm{a}$ & $37.7 \mathrm{a}$ & $100.6 \mathrm{a}$ & $45.8 \mathrm{c}$ & $32.6 \mathrm{~b}$ \\
$\mathrm{CI}$ & $122.8 \mathrm{a}$ & $40.5 \mathrm{~b}$ & $35.5 \mathrm{~b}$ & $109.5 \mathrm{a}$ & $53.3 \mathrm{a}$ & $38.4 \mathrm{a}$ \\
$\mathrm{SA}$ & $127.3 \mathrm{a}$ & $45.1 \mathrm{a}$ & $24.5 \mathrm{c}$ & $106.5 \mathrm{a}$ & $46.3 \mathrm{bc}$ & $31.2 \mathrm{~b}$ \\
$\mathrm{CA}$ & $118.4 \mathrm{a}$ & $42.9 \mathrm{ab}$ & $33.8 \mathrm{~b}$ & $102.3 \mathrm{a}$ & $49.2 \mathrm{~b}$ & $39.1 \mathrm{a}$ \\
\hline C.V. $(\%)$ & 25.54 & 10.38 & 7.02 & 13.49 & 7.36 & 12.77 \\
\hline
\end{tabular}

SI: Com irrigação normal e sem cálcio; CI: Com irrigação normal e com cálcio; SA: Alagado e sem cálcio; CA: Alagado e com cálcio; DEEAb: Densidade estomática na Epiderme Abaxial; DPEEAb: Diâmetro Polar dos Estômatos da Epiderme Abaxial; DEEEAb: Diâmetro Equatorial dos Estômatos da Epiderme Abaxial. DEEAd: Densidade Estomática na Epiderme Adaxial; DPEEAd: Diâmetro Polar dos Estômatos da Epiderme Adaxial; DEEEAd: Diâmetro Equatorial dos Estômatos da Epiderme Adaxial. Médias seguidas de mesma letra, na coluna, não diferem entre si pelo teste de Tukey a $5 \%$ de probabilidade. 
A aplicação de cálcio e o alagamento promoveram um aumento significativo no espessamento da nervura mediana de folhas do milho "Saracura" em relação ao controle (Tabela 2, Figuras 1A, 1B, 1C, 1D). Essa resposta está relacionada, principalmente, com o aumento do parênquima fundamental, uma vez que os feixes vasculares não sofreram alterações em seus diâmetros à exceção do tratamento em que as plantas receberam cálcio e não foram alagadas. Stoyanova et al. (2002), estudando o efeito de seca e alagamento do solo sobre a espessura dos feixes vasculares em folhas de milho, cultivar Knezha 611 2L, também não observaram diferenças significativas nesse parâmetro. $\mathrm{O}$ mesmo foi observado nos tecidos vasculares de raízes do milho "Saracura" que estiveram sob alagamento (Ferrer, 2003).

Apesar da pouca variação do tamanho dos feixes vasculares como um todo, observou-se que o metaxilema mostrou-se significativamente maior nas plantas cultivadas sem cálcio e sem alagamento, diminuindo, principalmente, com o alagamento (Tabela 2). De acordo com Baas e Schweingruber (1987); Carlquist (1988); Alves e Angyalossy-Alfonso (2000), os fatores ambientais afetam as dimensões e até mesmo o arranjo dos elementos vasculares. Quando a planta está sujeita a algum tipo de estresse, a diminuição dos vasos pode garantir um aumento na segurança do transporte (Baas, 1982), uma vez que o estreitamento dos vasos mantém a coluna de água em alta tensão, em decorrência de uma maior área de contato, proporcional ao volume de água, causada pela maior quantidade de moléculas de água aderidas à parede celular (Carlquist, 1989). Alves et al. (2001) também constatou uma diminuição do metaxilema dos vasos foliares em híbridos 4430 de Trandescantia em resposta à poluição atmosférica. Esse mesmo efeito foi encontrado por Vasellati et al. (2001), estudando o efeito da seca sobre os vasos de raízes de Paspalum dilatatum.

Cerca de $37 \%$ da espessura da lâmina foliar corresponde à epiderme das duas superfícies, onde a adaxial refere-se a $21 \%$ e a abaxial a $16 \%$. O cálcio promoveu um aumento significativo do espessamento da epiderme quando comparado com os tratamentos sem a adição desse elemento em plantas nas mesmas condições de irrigação (Tabela 2). Na cultivar de milho Knezha 611 2L, 30\% do espessamento da lâmina foliar correspondeu à epiderme das duas superfícies. Neste caso, a epiderme da superfície adaxial foi mais espessa que a abaxial nas condições de seca e alagamento (Stoyanova et al., 2002), confirmando

TABELA 2. Espessura $(\mu \mathrm{m})$ de tecidos e células de milho "Saracura" na época de floração, submetido às condições de alagamento e aplicação de cálcio ao solo. Lavras, 2004.

\begin{tabular}{ccccccccc}
\hline Trat. & $\begin{array}{c}\text { Nervura } \\
\text { Mediana }\end{array}$ & $\begin{array}{c}\text { Feixe } \\
\text { Vascular }\end{array}$ & Metaxilema & Mesofilo & $\begin{array}{c}\text { Epiderme } \\
\text { Adaxial }\end{array}$ & $\begin{array}{c}\text { Epiderme } \\
\text { Abaxial }\end{array}$ & DPCB & DECB \\
\hline SI & $921.6 \mathrm{~b}$ & $281.8 \mathrm{~b}$ & $85.8 \mathrm{a}$ & $178.5 \mathrm{~b}$ & $30.5 \mathrm{~b}$ & $26.2 \mathrm{bc}$ & $72.8 \mathrm{~b}$ & $115.7 \mathrm{a}$ \\
$\mathrm{CI}$ & $1152.0 \mathrm{a}$ & $301.4 \mathrm{a}$ & $78.4 \mathrm{~b}$ & $184.4 \mathrm{a}$ & $37.7 \mathrm{a}$ & $30.9 \mathrm{a}$ & $70.9 \mathrm{~b}$ & $122.2 \mathrm{a}$ \\
$\mathrm{SA}$ & $1189.9 \mathrm{a}$ & $281.8 \mathrm{~b}$ & $70.9 \mathrm{c}$ & $155.4 \mathrm{c}$ & $32.9 \mathrm{~b}$ & $23.5 \mathrm{c}$ & $98.9 \mathrm{a}$ & $127.8 \mathrm{a}$ \\
$\mathrm{CA}$ & $1280.3 \mathrm{a}$ & $271.5 \mathrm{~b}$ & $69.1 \mathrm{c}$ & $152.1 \mathrm{c}$ & $39.8 \mathrm{a}$ & $29.3 \mathrm{ab}$ & $76.5 \mathrm{~b}$ & $128.8 \mathrm{a}$ \\
\hline C.V. $(\%)$ & 14.47 & 5.75 & 9.16 & 6.28 & 11.85 & 16.05 & 13.71 & 17.93 \\
\hline
\end{tabular}

SI: Com irrigação normal e sem cálcio; CI: Com irrigação normal e com cálcio; SA: Alagado e sem cálcio; CA: Alagado e com cálcio; DPCB: Diâmetro Polar das Células Buliformes; DECB: Diâmetro Equatorial das Células Buliformes. Médias seguidas de mesma letra, na coluna, não diferem entre si pelo teste de Tukey a 5\% de probabilidade. 
o que foi observado no presente trabalho. Segundo Ferrer (2003), a espessura da rizoderme do milho "Saracura" diminuiu significativamente quando submetida às condições de alagamento. Entretanto, observou-se neste trabalho que o efeito da diminuição da espessura da epiderme foliar, nas duas superfícies, foi em função da ausência de cálcio e não do efeito da disponibilidade de água no solo (Tabela 2).

$\mathrm{O}$ mesofilo em plantas que foram alagadas foi significativamente menor quando comparado com aquelas não alagadas. Nestas, $o$ cálcio promoveu um espessamento maior dessa região (Tabela 2). É possível que a plasticidade na variação do mesofilo esteja associada com o genótipo, uma vez que, Stoyanova et al. (2002) não observaram mudanças significativas na espessura do mesofilo de milho, cultivar Knezha 611 2L, submetido às condições de alagamento.

O efeito de condições de estresse é variável sobre as modificações na espessura do mesofilo. Ferris et al. (1996), estudando o efeito do estresse causado por altas temperaturas, também não observou mudanças significativas no mesofilo de Lolium perenne. No entanto, observou-se diminuição do mesofilo em plantas submetidas a ambientes com alta concentração de poluentes (Alves, 2001) ou de sais (Hwang e Chen, 1995).

As modificações estruturais observadas nas folhas do milho "Saracura" BRS - 4154, induzidas pelas condições experimentais deste trabalho, podem contribuir significativamente para o sucesso do seu cultivo nas condições de solos inundados, uma vez que a plasticidade morfo-anatômica está intrinsecamente relacionada à adaptabilidade vegetal às condições ambientais adversas. A plasticidade anatômica foliar desta cultivar à presença de cálcio no solo pode contribuir para uma maior sobrevivência das plantas, assim como promover condições adequadas para o crescimento vegetativo de plantas desta cultivar em solos alagados.

\section{Conclusão}

As folhas da cultivar de milho "Saracura" BRS - 4154 apresentam plasticidade morfo-anatômica às condições de alagamento e à aplicação de cálcio ao solo, podendo contribuir desta forma para o seu cultivo em solos com baixa pressão de oxigênio e ter sua sobrevivência e crescimento vegetativo influenciados pelo teor de cálcio contido no solo.

\section{Literatura Citada}

ALVES, E.S.; ANGYALOSSY-ALFONSO, V. Ecological trends in the wood of some Brazilian species 1: growth rings and vessels. IAWA Journal, Leiden, 21:3-30. 2000.

ALVES, E. S.; GIUSTI, P. M.; DOMINGOS, M. Anatomic studies on Tradescantia hibrid clone 4430 leaves: changes caused by urban air pollution. Revista Brasileira de Botânica, São Paulo, vol.24, no.4, suplem., p.561-566. Dec. 2001.

ALVES, J. D.; MAGALHÃES, M. M.; GOULART, P. F. P.; DANTAS, B. F.; GOUVÊA, J. A; PURCINO, R. P; MAGALHÃES, P. C.; FRIES, D. D.; LIVRAMENTO, D. E.; MEYER, L. E.SEIFFERT, M.; SILVEIRA, T. Mecanismos de tolerância da variedade de milho "Saracura" (BRS 4154) ao alagamento. Revista Brasileira de Milho e Sorgo, Sete Lagoas, v. 1, n. 1, p. 3340, jan/abr. 2002.

BAAS, P. Systematic, phylogenetic and ecological wood anatomy - History and perspectives. In: New perspectives in wood anatomy. (P. Baas, ed.). The Hangue Martinus Nijhoff Publishers, Leiden, p.23-58. 1982. 
BAAS, P. \& SCHWEINGRUBER, F.H. Ecological trends in the wood anatomy of trees, shrubs and climbers from Europe. IAWA Bulletin, Leiden, 8:245-274. 1987.

BENNETT, J.P., RASSAT, P., BERRANG, P. \& KARNOSKY, D.F. Relationships between leaf anatomy and ozone sensitivity of Fraxinus pennsylvanica Marsh. and Prunus serotina Ehrh. Environmental and Experimental Botany, Elmsford, 32:33-41. 1992.

CARLQUIST S. Adaptative wood anatomy of chaparral shrubs. In: KEELEY S. C. (Ed.) The California chaparral: paradigms reexamined. Natural History Museum of Los Angeles Country. Sciences Series, 34. Los Angeles: SpringerVerlag. 1989.

CARLQUIST, S. Comparative wood anatomy: systematic, ecological and evolutionary aspects of dicotyledons wood. Springer Verlag, Berlin. 1988.

DAMARTY, M.; MORUAN, C.; THELLIER, M. Calcium and Cell. Plant Cell Environmental, Oxford, v. 7, p. 441-448, 1984.

DREW, M. C.; LYNCH, J. M.; Soil anaerobiosis, microorganisms and root function. Annual Review of Phytopathology, Palo Alto, v. 18, p. 37-66, 1988.

EMPRESA BRASILEIRA DE PESQUISA AGROPECUÁRIA. Centro Nacional de Pesquisa de Solo. (Rio de Janeiro, R.J.) Sistema brasileiro de classificação de solos. Brasília: Embrapa Solos, 1999, 412p.

ESAU, K. Anatomia das plantas com sementes. $15^{\mathrm{a}}$ reimpresão. São Paulo, Edgard Blucher, 2000. 293 p.
FERRER, J. L. R. O cálcio na tolerância do milho (Zea mays L.) "Saracura'BRS-4154 ao algamento do solo em condições de campo e casa-de-vegetação. 200349 p. Dissertação (Mestrado) - Universidade Federal de Lavras, Lavras, M.G.

FERRIS, R.; NIJS, I.; BEHAEGHE, T.; IMPENS, I. Elevated $\mathrm{CO} 2$ and Temperature have Diåerent Eåects on Leaf Anatomy of Perennial Ryegrass in Spring and Summer. Annals of Botany, London, 78: 489-497, 1996

FLOWERS, T. J.; HAJIBAGHERI, M. A.; CLIPSON, N. T. W. Halophytes. The Quarterly Review of Biology, Chicago, 61: 313-337. 1986.

GIBBS, P. E.; LEITÃO FILHO, H. F. Floristic composition of on area of gallery Forest near Mogi-Iguaçu, state of São Paulo, S. E. Brazil. Revista Brasileira de Botânica, São Paulo, v. 1, n. 2, p. 151-156, 1978.

GILL, C. J. The flooding tolerance of woody species - a review. Forestry Abstracts, New York, v. 31, p. 671-688, 1970.

GRANT, G. T.; MORRIS, D. A.; REES, P. J. P.; SMITH, K. A. Biological intaractions between polusaccharides and divalent cations: The egg bos model. FEBS Letters, Amsterdam, v. 32, n. 1, p. 195-198, 1973.

HEPLER, P. K.; WAYNE, R. O. Calcium and plant development. Annual Rewiew Plant Physiology and Plant Molecular Biology, Palo Alto, v. 36, p. 397-439, 1985.

HWUANG, H. H.; CHEN, S. C. Anatomical responses in Kandelia candel (L.) Druce seedlings growing in the presence of different concentrations of $\mathrm{NaCl}$. Botanical Bulletin of Academia Sinica, Taipei, 36: 181-188. 1995. 
JACKSON, M. B.; DREW, M. C. Effects of flooding on growth and metabolism of herbaceous plants. In: KOSLOWSKI, T. T. Flooding and plant growth. Orlando: Academic Press, p. 47-128, 1984.

JOHANSEN, D. A. Plant microtechnique. $2^{\text {a }}$ Ed. Mc Graw-Hill Publishing Company LTD, New York, 1940, 523 p.

KOZLOWSKI, T. T. Response of woody plants to flooding. In: KOZLOWSKI, T. T. Flooding and Plant Growth. London: Academic Press, p. 129-163, 1984.

KRAUS, J. E.; ARDUIN, M. Manual básico de métodos em morfologia vegetal. Seropédica, $\mathrm{R}$. J.: EDUR, 1997, 198 p.

LABOURIAU, L. G.; OLIVEIRA, J. G.; SALGADO-LABOURIAL, M. L. Transpiração de Schizolobium parahyba (Vell) Toledo I. Comportamento na estação chuvosa, nas condições de Caeté, Minas Gerais. Anais da Academia Brasileira de Ciência, Rio de Janeiro, v. 23, p. 237257, 1961.

LARCHER, W. Ecofisiologia Vegetal. São Carlos: Rima, 2000. 531 p.

MAGALHÃES, P. C.; DURÃES, P. O. M.; CARNEIRO, N. P.; PAIVA, E. Fisiologia do Milho. Circular Técnica, 22. EMBRAPA, Sete Lagoas, Dez. 2002.

MENEZES, N. L.de; SILVA, D. da C.; PINNA, G. F. de M. de. Folha. In: APPEZZATO-DAGLÓRIA, B.; CARMELLO-GUERREIRO, S. M. (Ed.). Anatomia Vegetal. Viçosa: UFV. 2003. $438 \mathrm{p}$.

PARENTONI, S. N.; GAMA, E. E. G.; MAGNAVACA, R.; MAGALHÃES, P. C. Selection for tolerance to waterlogging in maiza
(Zea mays L.) In: Simpósio internacional sobre estresse abiótico. Belo Horizonte, M.G Brazil. P. 434-449. 1995.

SACHS, T.; NOVOPLANSKY, N.; KAGAN, M. L. Variable development and cellular patterning in the epidermis of Ruscus hypoglossum. Annals of Botany, London, 71: 237-243. 1993.

SELING, S.; WISSEMEIER, A. H.; CAMBIER, P.; CUTSEM, P. V. Calcium deficiency in popato (Solanum tuberosum ssp. tuberosum) leaves and its effects on teh pectic composition of the apaoplastic fluid. Physiologia Plantarum, Copenhagen, v. 109, n. 1, p. 44-50, May 2000.

SMALLWOOD, M. F.; CALVERT, C. M.; BOWLES, D. J. (Ed,) Plant responses to environmental stress. Oxford: Bios Scientific Publishers, 1999. 224 p.

STOYANOVA, D.; TCHAKALOVA, E.; YORDANOV, I. Influence of different soil moisture on antomy of maize leaves and ultrastructure of chloroplasts. Bulgarian Journal of Plant Physiology, Varna, 28(1-2), 11-20, 2002.

SUBBAIAH, C. C.; BUSH, D. S.; SACHS, M. M. Elevation of cytosolic calcium precedes anaoxic gene expression in maize suspension cultured cells. The Plant Cell, Rockville, v. 6, n. 12., p. 1747-1762., Dec. 1994b.

SUBBAIAH, C. C.; ZHANG, J. SACHS, M. M. Involvment in intracellular calcium in anaerobic gene expression and survival of maize sedlings. Plant Physiology, Rockville, v. 105, n. 1, p. 369376, May 1994a.

VASELLATI, V.; OESTERHELD, M.; LORETI, J. Effects of flooding and drought on the anatomy of Paspalum dilatatum. Annals of Botany, London, 88: 355-360, 2001. 
VITORINO, P. G.; AlVES, J. D.; MAGA- during hypoxia. Pesquisa Agropecuária BrasiLHÃES, P. C.; MAGALHÃES, M. M. LIMA, L. leira, Brasília, v. 36, n. 8, p. 1027-1035, ago. C. O.; OLIVEIRA, L. E. M. Flooding tolerance 2001. and cell wall alterations in maize mesocotyl 